\title{
Arylacetamide deacetylase knockout mice are sensitive to ketoconazole-induced hepatotoxicity and adrenal dysfunction
}

\author{
Mai Nagaoka ${ }^{1}$, Tatsuki Fukami ${ }^{1}$, Fumiya Kisui ${ }^{1}$, Takuya Yamada ${ }^{1}$, Yoshiyuki Sakai ${ }^{1}$, \\ Kiyomichi Tashiro ${ }^{1}$, Takuo Ogiso ${ }^{1}$, Keigo Konishi ${ }^{1}$, Shiori Honda ${ }^{1}$, Keiya Hirosawa ${ }^{1}$, \\ Masataka Nakano ${ }^{1}$, and Miki Nakajima ${ }^{1}$ \\ ${ }^{1}$ Kanazawa University
}

July 30, 2021

\begin{abstract}
Background and Purpose Orally administered ketoconazole rarely induces liver injury and adrenal dysfunction. In cellulo studies showed that a metabolite formed by arylacetamide deacetylase (AADAC)-mediated hydrolysis is relevant to ketoconazoleinduced cytotoxicity. This study tried to examine the significance of AADAC in ketoconazole-induced toxicity in vivo using Aadac knockout mice. Experimental Approach Wild-type and Aadac knockout mice orally received $150 \mathrm{or} 300 \mathrm{mg} / \mathrm{kg} / \mathrm{day}$ ketoconazole, and plasma parameters, the concentrations of ketoconazole and $N$-deacetylketoconazole in plasma and tissues, and hepatic mRNA levels of immune- and inflammatory-related factors were measured. The effects of pretreatment with corticosterone $(40 \mathrm{mg} / \mathrm{kg}$, s.c.) on ketoconazole-induced liver injury were also examined. Key Results In a study of a single oral administration of $150 \mathrm{mg} / \mathrm{kg}$ ketoconazole, the area under the plasma concentration curve values of ketoconazole and $N$-deacetylketoconazole in Aadac knockout mice were significantly higher and lower than those in wild-type mice, respectively. With the administration of ketoconazole (300 mg/kg/day) for 7 days, Aadac knockout mice showed higher mortality (100\%) than wild-type mice (42.9\%), with significantly higher plasma alanine transaminase and lower corticosterone levels, representing liver injury and adrenal dysfunction, respectively. In Aadac knockout mice, hepatic mRNA levels of immune- and inflammatoryrelated factors were increased by the administration of ketoconazole, and the increase was restored by the replenishment of corticosterone, which shows anti-inflammatory effects. Conclusion and Implications Aadac defects exacerbated ketoconazoleinduced liver injury by inhibiting glucocorticoid synthesis and enhancing the inflammatory response. This in vivo study revealed that the hydrolysis of ketoconazole by AADAC can mitigate ketoconazole-induced toxicities.
\end{abstract}

\section{Hosted file}

manuscript.docx available at https://authorea.com/users/428344/articles/532217-arylacetamidedeacetylase-knockout-mice-are-sensitive-to-ketoconazole-induced-hepatotoxicity-andadrenal-dysfunction 